\title{
Solid State Fermentation of Wheat Bran for Production of Glucoamylase by Aspergillus niger
}

\author{
Khushboo Gupta ${ }^{1 *}$, S. J. Nagar ${ }^{2}$ \\ ${ }^{1}$ Student, Department of Biochemical Engineering, HBTU, Kanpur, India \\ ${ }^{2}$ Professor, Department of Biochemical Engineering, HBTU, Kanpur, India
}

\begin{abstract}
*Address for Correspondence: Khushboo Gupta, Student, Department of Biochemical Engineering, HBTU, Kanpur, India

E-mail: anshul456gupta@gmail.com
\end{abstract}

Received: 16 Dec 2019/ Revised: 29 Jan 2020/ Accepted: 22 Jun 2020

\begin{abstract}
Background: Glucoamylase is an exo-enzyme use for the digestion of starch. It is widely used in production of glucose from starch, preparation of high fructose corn syrup (HFCS), baking industry, and alcohol production etc.

Methods: The present study was deals with the optimization $(\mathrm{pH}$, Temperature, inoculum size, inoculum age, carbon source, and nitrogen source) of the production media (wheat bran) for the production of glucoamylase from Aspergillus niger.

Results: optimized study suggested that the highest production of glucoamylase was observed at $350 \mathrm{C}$ temperature, $\mathrm{pH} 6$, inoculum size $15 \%$ at 5 day inoculum age. Best production of glucoamylase was observed as $0.6932 \mathrm{U} / \mathrm{ml}$ at the optimized condition.

Conclusion: Wheat bran is a good source for the production glucoamylase by A. niger. Glucoamylase can be produced by $A$. niger through solid state fermentation of wheat bran. Pre-treatment of wheat bran can improve the production of glucoamylase.
\end{abstract}

Key-words: - Aspergillus niger, Glucoamylase, Solid state fermentation, SSF, Wheat bran production of glucoamylase

\section{INTRODUCTION}

It is an exo-enzyme use for the hydrolysis of carbohydrate. Chemically, it is also known as $\alpha-1,4$ glucan glycohydrolase in which glucan refers to a sequence of connected glucose units and glycohydrolase made up of glycol and hydrolyse, which mines breakdown of glycosidic linkage present in between two glucose units. The enzyme identification code allocated to the Commission for Enzymes EC 3.2.1.3 by IUBM1992. Number 3 denotes the hydrolysis of large sugar molecule by the addition of water. While number 2 denote the glycosidase, which breaks the glycoside linkage present in between two glucose molecule ${ }^{[1]}$. Wheat bran is part of wheat so it contains many nutrients like protein, carbohydrate, fat, and fibres etc. the average content of protein, carbohydrate, fat, fibres and phosphorus are $16.4 \%, 65 \%, 4.5 \%, 6 \%$, and $1.29 \%$ respectively.

\section{How to cite this article}

Gupta K, Nagar SJ. Solid State Fermentation of Wheat Bran for Production of Glucoamylase by Aspergillus niger. SSR Inst. Int. J. Life Sci., 2020; 6(4): 2640-2645.

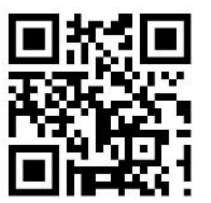

Access this article online https://ijils.com/
The $0.13 \%$ trace amount of calcium's obtained in previous report, given by the Islam et al. ${ }^{[2]}$. The glucoamylase can be produced by different type of microorganisms such as bacteria, fungus, and yeast. $A$. niger can produce different proteolytic enzyme, carbohydrate enzyme, and hydrolytic enzyme etc ${ }^{[3]}$.

The nutrient content of fibre can support the growth of the micro-organisms. The present study deals with the use of cost efficient wheat bran for the solid state fermentation for the production of glucoamylase and evaluated the production level.

\section{MATERIALS AND METHODS}

The present study was proceed from March 2019 to June 2019 in the Department of Biochemical Engineering, HBTU Kanpur, India.

Culture of Aspergillus niger- $A$. niger culture was procured from National Chemical Laboratory, Pune (Maharashtra), India. A. niger culture was grown on potato dextrose agar (PDA) media and incubated at $30^{\circ} \mathrm{C}$ for 5 days. 
Preparation of Inoculum- Spores were used to inoculate production medium. For sporulation, flasks containing 5 gram moistened substrate was inoculated from 5 days old slants followed by incubation for 5 days at $30^{\circ} \mathrm{C}$ temp. At the end of incubation period, the fermented mass mixed with $50 \mathrm{ml}$ of sterile saline water, containing $0.1 \%$ Twin 80 and then left for $20 \mathrm{~min}$. It was then filtered to remove unwanted components of medium from spores. Spore count was performed to adjust the count (5107 spores/ml) in spore suspension. For counting of spores, spread plate method was used after serial dilution of filtered containing spores ${ }^{[4]}$.

Glucoamylase enzyme Extraction- The glucoamylase enzyme was estimated using the method given by Cori ${ }^{[5]}$ and the reducing sugars liberated were determined by Dinitrosalicylic acid (DNSA) method that given by Miller [6].

Preparation of standard graph of Glucose- Taken different test tube and prepared the $1 \mathrm{ml}$ different concentrations $(0,0.2,0.4,0.6,0.8$, and $1 \mathrm{mg} / \mathrm{ml})$ of glucose by the help of distilled water and added to $1 \mathrm{ml}$ of DNS (Dinitrosalcilic acid) in each test tube and incubated the test tube in boiling water bath at $100^{\circ} \mathrm{C}$ for 10 min duration. After that cool the test tube and taken the OD at $540 \mathrm{~nm}$ wavelength ${ }^{[6]}$.

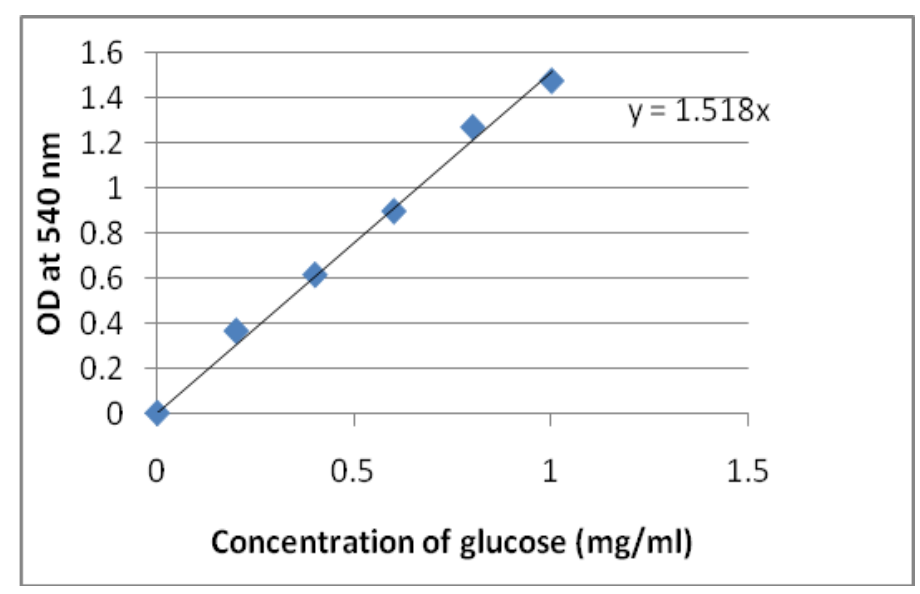

Fig. 1: Standard glucose curve of Glucose concentration

\section{Optimization of the fermentation parameters for glucoamylase production by using wheat bran as a substrate-}

Optimization of Carbon source- To study, the effect of the carbon source on production glucoamylase, media was prepared by using different $1 \%$ carbon source (glucose, fructose, maltose, starch, and sucrose) and media was inoculated by $A$. niger and incubated at $35^{\circ} \mathrm{C}$ for 5 days duration. The other fermentation parameters were kept constant.

Optimization of Nitrogen source- To study, the effect of the different nitrogen source on the production of glucoamylase, $1 \%$ of different nitrogen source (urea, peptone, yeast extract, malt extract, and ammonium sulphate) were added in different fermentation medium and media was inoculated by $A$. niger and incubated at $35^{\circ} \mathrm{C}$ for 5 days duration. The other fermentation parameters were kept constant ${ }^{[7]}$.

Optimization of Temperature- Effect of the temperature on glucoamylase production was also investigated to know the optimized temperature for enzyme production. For this, the inoculated medium was incubated for 7 days at different temp. $\left(25^{\circ} \mathrm{C}, 30^{\circ} \mathrm{C}, 35^{\circ} \mathrm{C}, 40^{\circ} \mathrm{C}\right.$, and $\left.45^{\circ} \mathrm{C}\right)$. The other fermentation parameters were kept constant [8].

Optimization of pH- Effect of initial $\mathrm{pH}$ on glucoamylase production was investigated to know the optimum $\mathrm{pH}$ for enzyme production. For this study, initial $\mathrm{pH}$ of medium was adjusted to different initial $\mathrm{pH}$ value $(3,4$, $5,6,7$, and 8$)$ at the end of the incubation period $\left(7^{\text {th }}\right.$ days) enzyme activity was determined. The other fermentation parameters were kept constant ${ }^{[9]}$.

Inoculum age- Inoculum of different ages (1 to 7 days old) was used to study the effect of inoculum age on glucoamylase production. The other fermentation parameters were kept constant ${ }^{[10]}$.

Inoculum level- Effect of inoculum level on glucoamylase production was examined to know the inoculum size for best enzyme production. Different inoculum levels between $5-30 \%(5,10,15,20,25$, and 30$)$ were used and at the end of incubation period ( 7 days) the enzyme activity was measured. Rest of the fermentation parameters were maintained constant ${ }^{[11]}$.

\section{RESULTS}

Effect of carbon with wheat bran- To study, effect of the carbon source on production glucoamylase, media was prepared by using $1 \%$ different carbon source (glucose, fructose, maltose, starch, and sucrose) and media was inoculated by $A$. niger and incubated at $35^{\circ} \mathrm{C}$ for 5 days. As seen from Fig. 2, the maximum enzyme activity 
$(0.450913 \mathrm{U} / \mathrm{ml})$ was found at fructose as a carbon source. The lowest activity $(0.316658 \mathrm{U} / \mathrm{ml})$ was at starch as carbon source. The enzyme activity of other carbon source glucose, maltose and sucrose, was 0.387952, 0.339805 , and 0.360175 respectively.

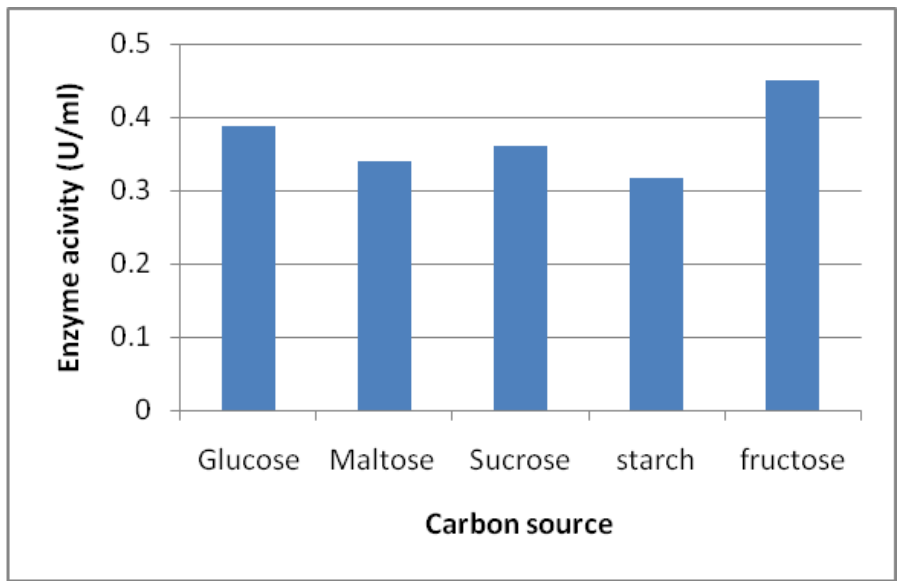

Fig. 2: Production of glucoamylase at different carbon supplements with wheat bran

Effect of nitrogen with wheat bran- To study, the effect of the different nitrogen source on the production of glucoamylase, $1 \%$ of different nitrogen source (urea, peptone, yeast extract, malt extract, and ammonium sulphate) were added in different fermentation medium and media was inoculated by $A$. niger and incubated at $35^{\circ} \mathrm{C}$ for 5 days.

As seen from Fig. 3, the maximum enzyme activity $(0.449987 \mathrm{U} / \mathrm{ml})$ was found at peptone as a nitrogen source. The lowest activity $(0.299992 \mathrm{U} / \mathrm{ml})$ was at urea as a nitrogen source. The enzyme activity of another nitrogen source yeast extract, malt extract, and ammonium sulphate were 0.417581, 0.391656, and 0.412026 , respectively.

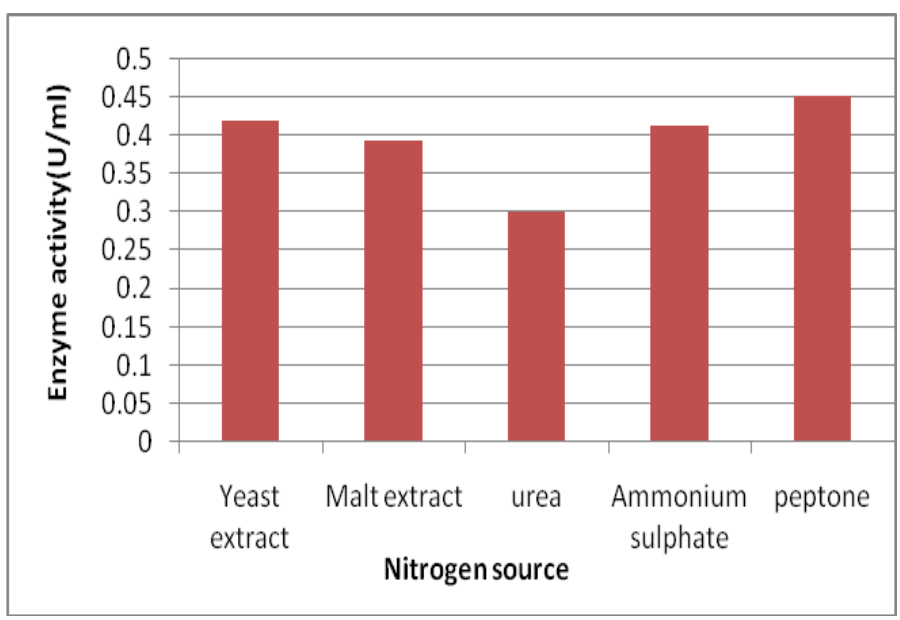

Fig. 3: Production of glucoamylase at different nitrogen supplements with wheat bran
Effect of temperature- As seen from Fig. 4, the maximum enzyme activity $(0.425914 \mathrm{U} / \mathrm{ml})$ was found at temperature $35^{\circ} \mathrm{C}$. The enzyme activity $(0.2036 .98 \mathrm{U} / \mathrm{ml})$ on lower temperature was observed at $25^{\circ} \mathrm{C}$ temperature. Between temperatures $25^{\circ} \mathrm{C}$ to $45^{\circ} \mathrm{C}$, the enzyme activities were $(0.361101,0.333324$ and $0.287029 \mathrm{U} / \mathrm{ml}$ ) at temp. $30^{\circ} \mathrm{C}, 40^{\circ} \mathrm{C}$ and $45^{\circ} \mathrm{C}$ respectively.

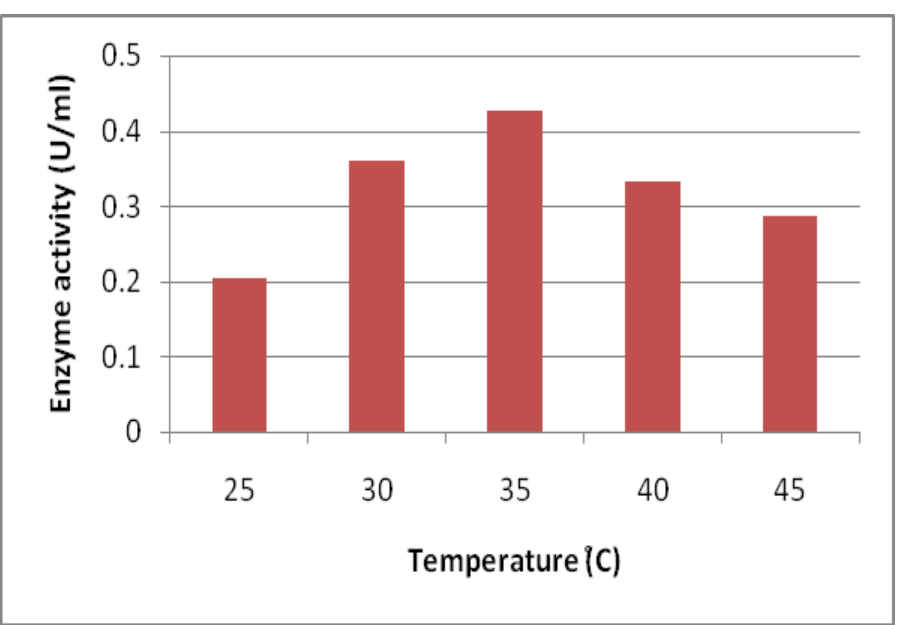

Fig. 4: Production of glucoamylase at different Temp.

Effect of pH- As seen from Fig. 5, the maximum enzyme activity $(0.444432 \mathrm{U} / \mathrm{ml})$ was found at $\mathrm{pH} 6.0$. The enzyme activity on lower activity $(0.194439 \mathrm{U} / \mathrm{ml})$ was observed to be at $\mathrm{pH} 3.0$. Between $\mathrm{pH} 3.0$ to 8.0 , the enzyme activities were $(0.268511,0.333324,0.398137$, and $0.314806 \mathrm{U} / \mathrm{ml}$ ) at $\mathrm{pH} \mathrm{4,5,7}$ and 8 respectively.

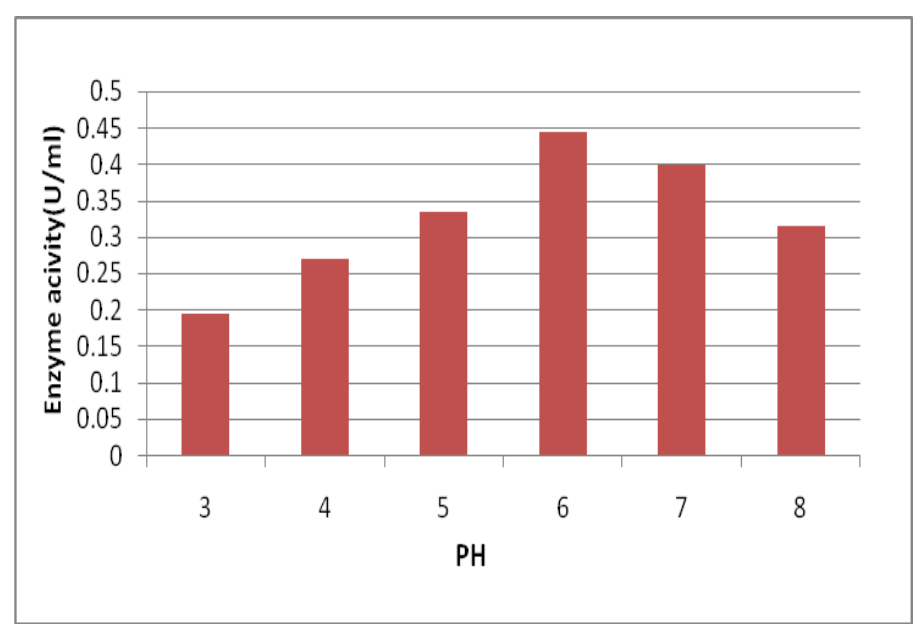

Fig. 5: Production of glucoamylase at different $\mathrm{pH}$

Effect of inoculum age- As seen from Fig. 6, the maximum enzyme activity $(0.459246 \mathrm{U} / \mathrm{ml})$ was found inoculum age at 5 days. The lower enzyme activity $(0.362027 \mathrm{U} / \mathrm{ml})$ was observed at 2 days inoculum. Between inoculum ages 1 day to 7 day, the enzyme 
activities were $0.327769,0.348138,0.399989,0.412026$ and $0.378693 \mathrm{U} / \mathrm{ml}$ at inoculum age $1,3,4,6$ and 7 day respectively.

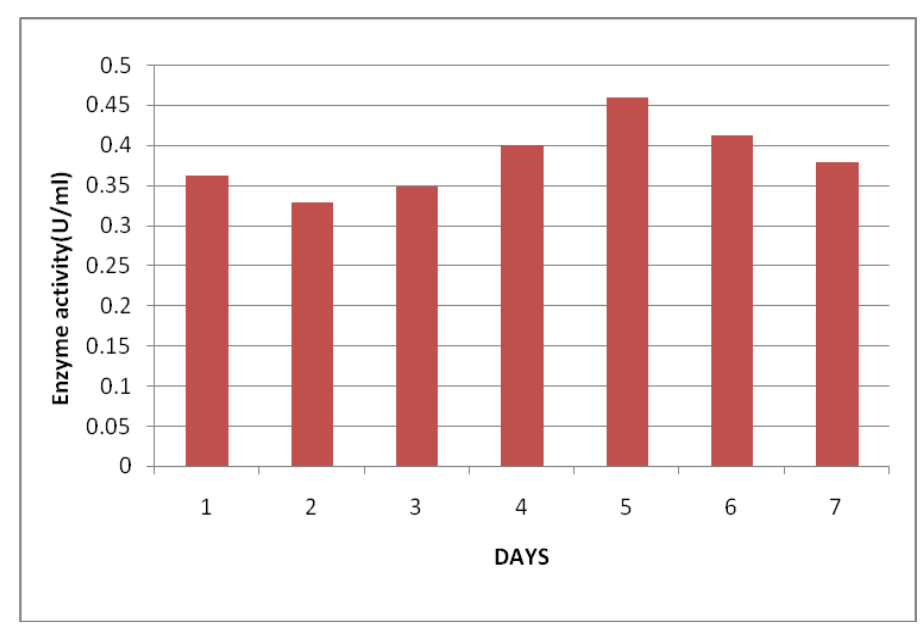

Fig. 6: Production of glucoamylase at different inoculum age

Effect of inoculum level- As can be seen from Fig. 7, the maximum enzyme activity $(0.450913 \mathrm{U} / \mathrm{ml})$ was found at inoculum level at $15 \%$. The lowest enzyme activity $(0.299992 \mathrm{U} / \mathrm{ml})$ was found at $5 \%$ inoculum level. Between inoculum level $5 \%$ to $30 \%$, the enzyme activities were $0.42221,0.419433,0.380545$, and $0.3601751 \mathrm{U} / \mathrm{ml}$ at inoculum level 10, 20, 25 and 30\% respectively.

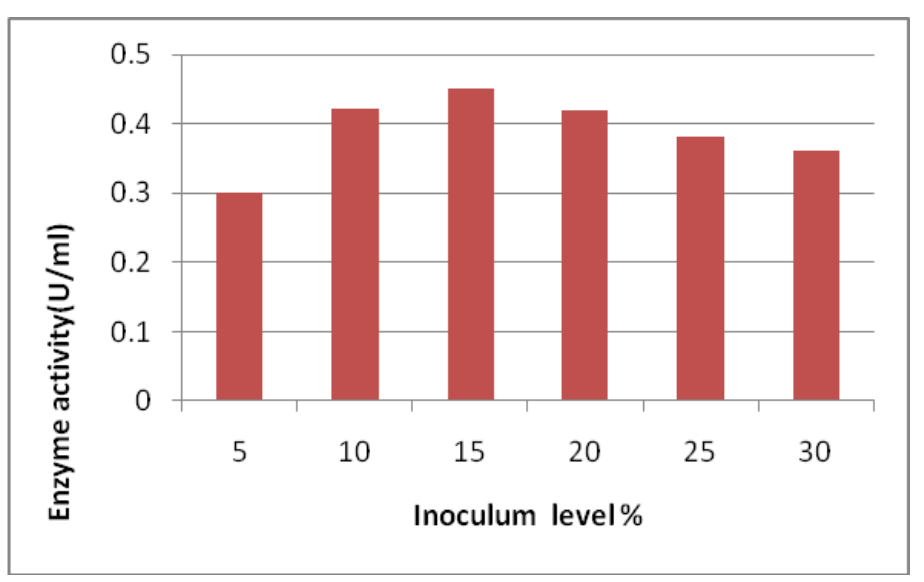

Fig. 7: Production of glucoamylase at different inoculum level (\%)

Production of glucoamylase at optimized conditionFrom the above study, we got the best condition for the production of glucoamylase from $A$. Niger sp. The production of glucoamylase at fructose as a carbon source, peptone as a nitrogen source the $\mathrm{pH}$ of the media was 6 and inoculum level 15\%. Media was inoculated with 5 day old culture. At given condition production was observed as $0.6932 \mathrm{U} / \mathrm{ml}$.

\section{DISCUSSION}

Solid state fermentation of wheat bran give a clear idea to utilize food waste for the production of glucoamylase but the amount of glucoamylase produced during this process was very less. The additional carbon and nitrogen source was given to support the initial growth of $A$. niger. Pavezzi et al. ${ }^{[12]}$ reported that potato starch as a best substrate for the production of glucoamylase (8.3 $\mathrm{U} / \mathrm{ml})$ by $A$. awamori in combination with Saccharomyces cerevisiae, while we have reported, the maximum production of $0.6932 \mathrm{U} / \mathrm{ml}$, there was great difference in the concentration of glucoamylase, this may be due to different organism or due to different substrate.

The current study also suggested similar results by some researchers i.e. Pavezzi et al. ${ }^{[6]}$, Norouzian et al. ${ }^{[12]}$ and, Adefisoye et. al. ${ }^{[13]}$ had suggested that $\mathrm{pH} 6$ was taken for the maximum production of glucoamylase.

The similar study was done by Anto et al. ${ }^{[14]}$ suggested that temperature play a violet role in the production of glucoamylase, the maximum production of glucoamylase was at $55^{\circ} \mathrm{C}$ while current study suggested $35^{\circ} \mathrm{C}$ for the maximum production, this may be due to difference in microorganism. Another previous research study done by Lakshmi et al. ${ }^{[15]}$ that suggested that maximum production of glucoamylase had produced by nitrogen source i.e. peptone (a organic compound). Inoculum age and inoculum size change with the change of microorganism different study suggest 3 day to 7 day inoculum age and 5 to $25 \%$ inoculum size were given by other previous studies i.e. Kumar et al. ${ }^{[16]}$; Selvakumar et al. ${ }^{[17]}$; Papagianni et al. ${ }^{[18]}$; Kumar et al. ${ }^{[19]}$; Arasaratnam et al. ${ }^{[20]}$. While this study suggest 5 day inoculum age and $15 \%$ inoculum size, which are similar to the above study.

\section{CONCLUSIONS}

The use of wheat bran as substrate for the production of glucoamylase by $A$. niger can be a great idea for the utilization of waste food material. For the grater production of glucoamylase the solid state media of wheat bran was supplemented with different carbon source and nitrogen source. The maximum production of glucoamylase was observed at fructose as a carbon source, peptone at a nitrogen source. Apart from carbon and nitrogen source some other factor likes $\mathrm{pH}(6)$, inoculum level (15\%) and inoculum age (5 day) also played a vital role in the production glucoamylase. 
The present study revealed that wheat bran can be use as substrate for the $A$. niger for the production of glucoamylase but the production was very less, this may be due to the complex nature of the wheat bran. The production of glucoamylase can be increase by pretreatment of wheat bran.

\section{ACKNOWLEDGMENTS}

We would like to thank my supervisor Professor S. J. Nagar Sir and all teaching and non-teaching staff of Department of Biochemical Engineering.

\section{CONTRIBUTION OF AUTHORS}

Research concept- S. J. Nagar

Research design- Khushboo Gupta

Supervision- S. J. Nagar

Materials- Khushboo Gupta

Data collection- Khushboo Gupta

Data analysis and Interpretation- Khushboo Gupta, S. J. Nagar

Literature search- Khushboo Gupta

Writing article- Khushboo Gupta

Critical review- S. J. Nagar

Article editing- S. J. Nagar

Final approval- S. J. Nagar

\section{REFERENCES}

[1] Reilly PJ. Protein engineering of glucoamylase to improve industrial performance-A review. StarchStarke, 1999; 51(8-9): 269-74.

[2] Islam MS, Khan M, Reza A. Effect of wheat bran substitution for corn and dehydrated Alfalfa on finishing Lambs. Bangladesh J. Animal Sci., 2009; 38(1-2): 61-66.

[3] Nielsen KF, Mogensen JM, Johansen M, Larsen TO, Frisvad JC. Review of secondary metabolites and mycotoxins from the Aspergillus niger group. Analytical Bioanalytical. Chem., 2009; 395(5): 1225-42.

[4] Espinel-Ingroff A, Kerkering TM, Spectrophotometric method of inoculum preparation for the in vitro susceptibility testing of filamentous fungi.J. Clin. Microbiol., 1991; 29(2): 393-94.

[5] Miller GL. Modified DNS method for reducing sugars. Analytical chem., 1959; 31(3): 426-28.

[6] Pavezzi FC, Gomes E, Silva RD. Production and characterization of glucoamylase from fungus Aspergillus awamori expressed in yeast
Saccharomyces cerevisiae using different carbon sources. Braz. J. Microbiol., 2008; 39(1): 108-14.

[7] Khan A, Butt WA, Ali S, Qadeer MA. Effect of carbon and nitrogen sources on xylanase production by mutant strain of Aspergillus niger GCBMX-45. J. Biol. Sci., 2002; 2(2): 143-44.

[8] Shivanna GB, Venkateswaran G. Phytase production by Aspergillus niger CFR 335 Aspergillus ficuum SGA 01 through submerged and solid-state fermentation. Sci. World J., 2014; 392615.

[9] Vu VH, Pham TA, Kim K. Improvement of fungal cellulase production by mutation and optimization of solid state fermentation. Mycobiol., 2011; 39(1): 20-25.

[10]Kaur P, Satyanarayana T. Production and starch saccharification by a thermostable and neutral glucoamylase of a thermophilic mould Thermomucor indicae-seudaticae. World J. Microbiol. Biotechnol., 2004; 20(4): 419-25.

[11]Kumar MS, Lakshmi MV, Sridevi V. Production and optimization of Glucoamylase from wheat bran by Aspergillus oryzae NCIM 1212 under Solid State Fermentation. Int. J. Appl. Innov. Eng. Manage, 2013; 2(10): 318-23.

[12]Norouzian D, Akbarzadeh A, Scharer JM, Young MM. Fungal glucoamylases. Biotechnol. Adv., 2006; 24(1): 80-85.

[13]Adefisoye SA, Sakariyau AO Production of Glucoamylase by Aspergillus niger in Solid State Fermentation, Adv. Biol. Res., 2018, 12 (1): 07-11.

[14]Anto H, Trivedi UB, Patel KC. Glucoamylase production by solid-state fermentation using rice flake manufacturing waste products as substrate. Bioresource Technol., 2006; 97(10): 1161-66.

[15]Lakshmi MMVC, Jyothi P. Production and optimization of Glucoamylase from Aspergillus oryzae NCIM 1212 using wheat bran, varying chemical parameters under solid state fermentation. Int. J. Curr. Microbiol. App. Sci., 2014; 3(5): 70-76.

[16]Kumar MS, Lakshmi MV, Sridevi V. Production and optimization of Glucoamylase from wheat bran by Aspergillus oryzae NCIM 1212 under Solid State Fermentation. Int. J. Appl. Innov. Eng. Manage, 2013; 2(10): 318-23.

[17] Selvakumar P, Ashakumary L, Pandey A. Biosynthesis of glucoamylase from Aspergillus niger by solid-state 
fermentation using tea waste as the basis of a solid substrate. Bioresour. Technol., 1998; 65(1-2): 83-85.

[18]Papagianni M, Moo-Young M. Protease secretion in glucoamylase producer Aspergillus niger cultures: Fungal morphology and inoculum effects. Process Biochem., 2002; 37(11): 1271-78.

[19]Kumar S, Kumar P, Satyanarayana T. Production of raw starch-saccharifying thermostable and neutral glucoamylase by the thermophilic mold Thermomucor indicae-seudaticae in submerged fermentation. Appl. Biochem. Biotechnol., 2007; 142(3): 221-30.

[20]Arasaratnam VA, Mylvaganam KE, Balasubramaniam KA. Glucoamylase production by Aspergillus niger in solid state fermentation with paddy husk as support. J. Food sci. Technol. Mysore, 2001; 38(4): 334-38. 